\title{
Adrenal and sex steroid receptor evolution: environmental implications
}

\section{E Baker}

Department of Medicine, 0823, University of California, San Diego, 9500 Gilman Drive, La Jolla, California 92093-0823, USA

(Requests for offprints should be addressed to M E Baker; Email: mbaker@ucsd.edu)

\begin{abstract}
The nuclear receptor family responds to a diverse group of ligands, including steroids, retinoids, thyroid hormone, prostaglandins and fatty acids. Previous sequence analyses of adrenal and sex steroid receptors indicate that they form a clade separate from other nuclear receptors. However, the relationships of adrenal and sex steroid receptors to each other and to their ancestors are not fully understood. We have used new information from androgen, estrogen, mineralocorticoid and progesterone receptors in fish to better resolve the phylogeny of adrenal and sex steroid receptors. Sequence divergence between fish and mammalian steroid receptors correlates with differences in steroid specificity, suggesting that phylogeny needs to be considered in evaluating the endocrine effects of xenobiotics. Among the vertebrate steroid receptors, the most ancient is the estrogen receptor.
\end{abstract}

The phylogeny indicates that adrenal and sex steroid receptors arose in a jawless fish or a protochordate and that changes in the sequence of the hormone-binding domain have slowed considerably in land vertebrates. The retinoid $\mathrm{X}$ receptor clade is closest to the adrenal and sex steroid receptor clade. Retinoid X receptor is noteworthy for its ability to form dimers with other nuclear receptors, an important mechanism for regulating the action of retinoid $\mathrm{X}$ receptor and its dimerization partners. In contrast, the adrenal and sex steroid receptors bind to DNA as homodimers. Moreover, unliganded adrenal and sex steroid receptors form complexes with heat shock protein 90. Thus, the evolution of adrenal and sex steroid receptors involved changes in protein-protein interactions as well as ligand recognition.

Fournal of Molecular Endocrinology (2001) 26, 119-125

\section{INTRODUCTION}

The adrenal and sex steroids: cortisol, aldosterone, estrogen, testosterone and progesterone, have a central role in development, reproduction and homeostasis in humans and other vertebrates (Evans 1988, DeGroot 1995, Mangelsdorf et al. 1995). These steroids act through nuclear receptors, which are a family of transcription factors that also includes receptors for retinoids, thyroid hormone, prostaglandins and fatty acids, as well as receptors without known ligand: the orphan receptors (Evans 1988, Mangelsdorf et al. 1995, Chambon 1996, Enmark \& Gustafsson 1996, Giguere 1999).

Sequence analyses show that the adrenal and sex steroid receptors are a distinct clade in the nuclear receptor family (Baker 1997, Escriva et al. 1997, 2000, Laudet 1997, Thornton \& Kelley 1998). This clade arose at the time that coincides with the origins of vertebrates and, indeed, steroid hormones may have had an important role in the early evolution of vertebrates and their subsequent survival of global catastrophes (Baker 1997). Phylogenetic analyses of the ligand-binding domain (Baker 1997) indicate that the estrogen receptor (ER) is the most ancient of the adrenal and sex steroid receptors, the progesterone receptor (PR) and androgen receptor (AR) cluster on one branch, and the glucocorticoid receptor (GR) and mineralocorticoid receptor (MR) cluster on another branch. However, the early events in steroid receptor evolution were poorly defined because there were few 'molecular fossils' from fish and because strong sequence conservation of steroid receptors from amphibia to mammals (Baker 1997, Laudet 1997, Thornton \& Kelley 1998) reduced the resolution at the base of the steroid receptor tree. This obstacle to a more complete phylogeny was removed with the recent reports of the sequences of fish AR (Todo et al. 1999, Takeo \& Yamashita 1999, Ikeuchi et al. 
1999), fish PR (Todo et al. 2000) and fish MR (Colombe et al. 2000).

We constructed a phylogeny of adrenal and sex steroid receptors that includes these newly determined fish steroid receptor sequences. We have found that the sequences of the hormone-binding domain in fish steroid receptors have diverged more from their orthologs in land vertebrates than amphibian and mammalian orthologs have from each other. This sequence divergence correlates with recently reported differences in ligand specificity between fish and land vertebrate steroid receptors. An important implication of our analysis is that phylogeny needs to be considered in evaluating the effects of environmental chemicals on steroid-responsive processes; that is, some chemicals will have different endocrine effects in mammals and fish.

We have also traced the steroid receptor clade to an ancestral retinoid $\mathrm{X}$ receptor (RXR), which forms heterodimers with a variety of nuclear receptors, but not with adrenal and sex steroid receptors (Glass 1994, Mangelsdorf et al. 1995, Chambon 1996, Enmark \& Gustafsson 1996, Giguere 1999). In contrast, adrenal and sex steroid receptors are active as homodimers in regulating gene transcription and, in the unliganded state, these steroid receptors bind heat shock protein 90 (HSP90) (Pratt \& Toft 1997). Thus, proteinprotein interactions as well as changes in ligand recognition were important in the evolution of adrenal and sex steroid receptors.

\section{MATERIALS AND METHODS}

\section{PSI-BLAST analysis}

Position-specific iterated basic local alignment research tool (PSI-BLAST) allows a search of GenBank on the National Library of Medicine website (www.ncbi.nlm.nih.gov/BLAST) with a probe that contains information about sequence conservation in several homologous proteins (Altshul et al. 1997). The first search is identical to a BLAST analysis. PSI-BLAST output has an option for choosing sequences that are collected and aligned for the next search of the database. For this search, PSI-BLAST constructs a scoring matrix that is based on the frequency of occurrence of amino acids at each position in the 'collection' of sequences. A search of the database with this position-specific matrix will uncover protein sequences that most resemble that of the protein collection. To determine the closeness of other nuclear receptors to the ER, we searched GenBank with the ligand-binding domain of eel ER- $\beta$. Then
TABLE 1. PSI-BLAST analysis of the estrogen-binding domain of the ER (database: nr 517973 sequences)

$\begin{array}{llll} & \text { Protein } & & \text { e-value } \\ \text { Accession number } & & \\ \text { BAA19851.1 } & \text { Eel ER- } \beta & \text { e-145 } \\ \text { P03372 } & \text { Human ER- } \alpha & \text { e-127 } \\ \text { Q92731 } & \text { Human ER- } \beta & \text { e-123 } \\ \text { AAD13610.2 } & \text { Trout ER- } \alpha & \text { e-122 } \\ \text { AAC99409.1 } & \text { Human ERR-2 } & 7 \mathrm{e}-37 \\ \text { P11474 } & \text { Human ERR-1 } & 7 \mathrm{e}-35 \\ \text { P28701 } & \text { Chick RXR- } \gamma & 4 \mathrm{e}-23 \\ \text { P51129 } & \text { Xenopus RXR- } \gamma & 6 \mathrm{e}-23 \\ \text { P06186 } & \text { Rabbit PR } & 6 \mathrm{e}-22\end{array}$

we added the sequences of trout ER- $\alpha$ and human ER- $\alpha$ and human ER- $\beta$ for the first iteration. These receptors were chosen after pairwise comparisons revealed that their estrogen-binding domains have from $55 \%$ to $65 \%$ sequence identity with each other.

\section{Phylogenic analysis}

The Feng \& Doolittle (1990) algorithm was used to construct a multiple alignment of the ligandbinding domain of adrenal and sex steroid receptors, estrogen-related receptor (ERR) and RXR. In this method, protein sequences are progressively aligned using the Dayhoff PAM-250 scoring matrix to assess pairwise similarity of each sequence with the others. The pairwise similarity scores are assembled into a distance matrix to construct a phylogenetic tree. The method of Fitch \& Margoliash (1967) is then used to obtain the branching order for the sequences. Branch lengths are calculated by linear regression analysis of the best fit of the pairwise distances and the branching order. Branch lengths are proportional to distances between proteins.

\section{RESULTS AND DISCUSSION}

\section{PSI-BLAST analyis}

Preliminary BLAST searches (data not shown) confirmed that among the adrenal and sex steroid receptors, the ER is the closest to other nuclear receptors. Thus, we constructed a PSI-BLAST probe of eel ER- $\beta$, human ER- $\alpha$, human ER- $\beta$ and trout ER- $\alpha$. The results of this analysis are shown in Table 1. As expected, ERR is closest to ER because, as the name ERR indicates, when this gene was cloned comparisons of its DNA-binding and putative ligand-binding domains with that of the ER indicated a close relationship (Enmark \& Gustafsson 1996, Giguere 1999). 
Interestingly, the next closest nuclear receptor is RXR. We used RXR as an outgroup for the phylogenetic analysis of adrenal and sex steroid receptors and ERR.

\section{Phylogenetic analysis}

Figure 1 shows a phylogenetic tree of adrenal and sex steroid receptors, ERR1, ERR2 and RXR- $\alpha$ constructed using the program of Feng \& Doolittle (1990). The phylogeny in Fig. 1 reveals some interesting features regarding relationships among vertebrate steroid receptors. The PR and AR cluster on one branch and the GR and MR cluster on another branch. The ER separated from the other steroid receptors at node IV. The ER is closer to node IV than the AR, PR, GR and MR. The slower change in the ER sequence indicates that it is under functional constraints, which is consistent with the estrogen response being the most ancient of the adrenal and sex steroid responses (Baker 1997). The phylogeny indicates that ER- $\alpha$ and ER- $\beta$ converge in an ancestral fish and that the estrogen response arose in jawless fish (hagfish or lamprey) or possibly earlier in amphioxus or in a tunicate. Escriva et al. (1997) used PCR to investigate the presence in chordates of genes with sequences that are homologous to DNA-binding domains of the ER and other steroid receptors. They found evidence for the AR, ER and GR in sharks and the PR in hagfish. The presence of PR in hagfish places the origin of adrenal and sex steroid receptors the the early Cambrian (Shu et al. 1999).

Figure 1 also indicates that the duplications at nodes I and II leading to the GR/MR and PR/AR clades respectively occurred in jawless fish or earlier, which is consistent with the PCR data of Escriva et al. (1997). The ancestral GR/MR, $\mathrm{PR} / \mathrm{AR}$ and ER are likely to lack functions that their orthologs have in land animals (Baker 1997). For example, the reproductive actions of ER in the placenta would not be found in fish. However, as discussed later, some ancient functions of the ER and other steroid receptors are likely to be important in modern animals and be influenced by xenobiotics.

Figure 1 shows that the molecular clock for the hormone-binding domain is not uniform among the various vertebrate steroid receptors. Considering that human and amphibian lines diverged about 350 million years ago and teleosts arose about 425 million years ago, the branch lengths between the hormone-binding domain in steroid receptors in land animals are much shorter than those between fish and amphibia. This indicates that there was a reduction in the rate of change in the steroid-

www.endocrinology.org

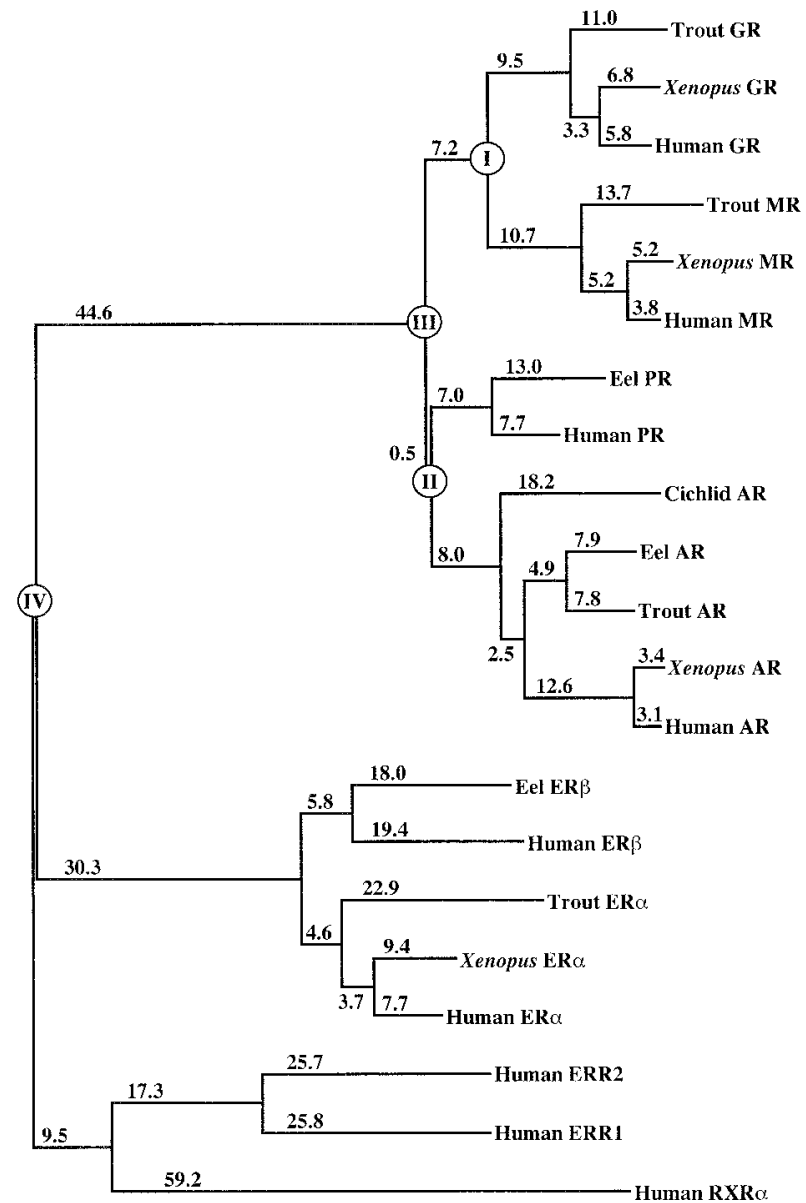

FIGURE 1. Phylogenetic analysis of adrenal and sex steroid receptors, ERRs and RXR. The Feng \& Doolittle (1990) algorithm was used to construct a multiple alignment of the ligand-binding domain of adrenal and sex steroid receptors, ERR and RXR. Branch lengths are proportional to distances between proteins. GenBank accession numbers for each receptor are: trout GR (P49843), Xenopus GR (P49844), human GR (P04150), trout MR (AF209873·1), Xenopus MR (Q91573), human MR (P08235), eel PR (BAA89539·1), human PR (P06401), cichlid AR (AAD25074·1), eel AR (BAA75464-1), trout AR (BAA32784·1), Xenopus AR (AAC97386.1), human AR (P10275), eel ER- $\beta$ (BAA19851·1), human ER- $\beta$ (Q92731), human ER- $\alpha$ (P03372), trout ER- $\alpha$ (AAD13610·2), Xenopus ER- $\alpha$ (P81559), human ERR1 (P11474), human ERR2 (AAC99409·1) and human RXR- $\alpha$ (P19793).

binding domain in land animals compared with fish. Among the adrenal and sex steroid receptors, the hormone-binding domain in the AR has been most conserved and the hormone-binding domain in the GR has been least conserved since the separation of amphibia and humans from a common ancestor. 
The length of the branches in the GR/MR clade indicates that the duplication at node I leading to the MR and GR arose in jawless fish or earlier. In land vertebrates, the MR regulates electrolyte balance under the influence of aldosterone. Aldosterone is not found in most fish. Aldosterone regulates electrolyte transport in amphibia. The MR has been found in tissues, in which aldosterone is not likely to regulate electrolyte balance. For example, in the brain the MR functions with the GR in the response to glucocorticoids (Ruel \& De Kloet 1985, Arriza et al. 1988, Funder 1996). This had led to an alternative name of GR-type 1 for the MR, to show that it responds to glucocorticoids (Arriza et al. 1987, 1988, Funder 1997) and to distinguish it from GR-type 2, the classical glucocorticoid receptor.

The ancient evolution of the GR-type 1/type 2 response to glucocorticoids can explain the presence of MR in tissues that are not involved in electrolyte balance. It also explains the slower changes in the GR-type 1 (MR) in amphibia and mammals compared with GR-type 2 in these animals as shown by the shorter branches in Fig. 1. The requirement that $\mathrm{MR}$ respond to aldosterone in kidney and gut, and to corticosterone and cortisol in brain and other tissues with GR-type I/type II physiology puts constraints on changes in the MR sequence.

ERR and ER arose by a duplication of a gene that was close to the RXR branch of the nuclear receptor superfamily. ERRs have functional similarities with the ER, such as binding to an estrogen response element and cross-talk between the ERR and ER responses (Luo et al. 1997, Vanacker et al. 1999a,b, Xie et al. 1999). Although ERR is thought to be a ligand-independent regulator of gene transcription (Enmark \& Gustafsson 1996, Luo et al. 1997, Giguere 1999, Xie et al. 1999), Vanacker et al. (1999b) recently presented indirect evidence that ERR is activated by a hydrophobic molecule. Identification of this molecule may provide clues to the ancestral ligand(s) that regulated ERR and ER.

The descent of the ER from RXR is interesting because it marks a change in both ligand-binding and protein-protein interactions. RXR is an unusual nuclear receptor because it acts as a partner for numerous other receptors including the thyroid hormone, retinoic acid and peroxisome proliferatoractivated receptors (Glass 1994, Mangelsdorf et al. 1995, Chambon 1996). In contrast, adrenal and sex steroid receptors bind to DNA as homodimers. Also, unliganded adrenal and sex steroid receptors are stabilized in complexes with HSP90 (Pratt \& Toft 1997) unlike RXR. Thus, changes in proteinprotein interactions as well as changes in the ligand led to the clade of receptors that responds to adrenal and sex steroids.

The genomes of Caenorhabditis elegans and Drosophila melanogaster contain nuclear receptors (Escriva et al. 2000). One of these, the ecdysone receptor in D. melanogaster recognizes a steroid hormone. Also $C$. elegans contains a nuclear receptor that has sequence similarity to the vitamin $\mathrm{D}$ receptor. However, proteins with sequence similarity to adrenal and sex steroid receptors have not been found in invertebrates. This is consistent with phylogenetic analyses, which indicate that the ecdysone and vitamin $\mathrm{D}$ receptors belong to nuclear receptor clades that branched off from the ancestral receptor before the origin of the adrenal and sex steroid receptors (Baker 1997, Laudet 1997, Escriva et al. 2000). The phylogeny shown in Fig. 1 and other analyses (Baker 1997, Escriva et al. 2000) indicate that the adrenal and sex steroid receptors arose in an ancient deuterostome.

\section{Fuzzy recognition of steroids in fish}

$5 \alpha$-Dihydrotestosterone (DHT) (Fig. 2), testosterone, 11ß-hydroxytestosterone and 11-ketotestosterone (11-keto T) bind to eel AR and activate gene transcription in cell culture (Ikeuchi et al. 1999, Takeo \& Yamashita 1999). Despite the broad recognition of androgens by eel AR, it is 11-keto'T that is the major circulating androgen in most fishes and the steroid that mediates the androgen response (Miura et al. 1991, Borg 1994). In contrast, DHT and testosterone are the principle androgens in amphibia and mammals. 11-keto'T is not an important androgen in amphibia and mammals. This indicates that steroid specificity for the AR changed during the transition from fish to land animals.

Corresponding to the change in the biologically active androgen during the transition from fish to land animals was a change in function of $11 \beta$ hydroxysteroid dehydrogenase (11 $\beta$-HSD). In fish, $11 \beta$-HSD catalyzes the synthesis of 11 -keto $T$ from 11ß-hydroxytestosterone (Miura et al. 1991, Borg 1994). In amphibia and mammals, 11ß-HSD regulates the interconversion of cortisol, the biological active glucocorticoid, and cortisone, an inactive glucocorticoid (Monder 1991, Edwards et al. 1996, Funder 1997). By inactivating cortisol in the kidney, $11 \beta$-HSD-type 2 prevents unwanted occupancy of the MR by cortisol, which allows aldosterone to regulate mineralocorticoid responsive genes (Monder 1991, Edwards et al. 1996, Funder 1997). Similarly, 11ß-HSD-type 2 prevents cortisol from inhibiting testosterone synthesis in testes. Thus, during the evolution from fish to amphibia, 


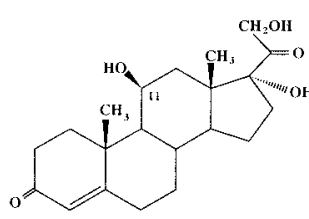

HYDROCORTISONE<smiles>CC(=O)C1CCC2C3CCC4=CC(O)CC[C@]4(C)C3CC[C@@]12C</smiles>

PROGESTERONE

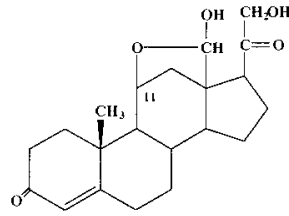

ALDOSTERONE<smiles>C[C@]12CC[C@@H](O)C=C1CCC1C2CC[C@]2(C)C1CC[C@@H]2O</smiles>

TESTOSTERONE

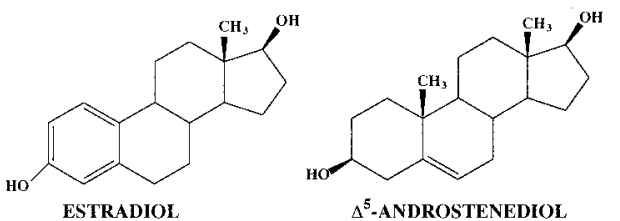

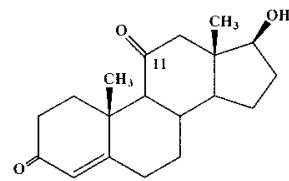

11-KETOTESTOSTERONE

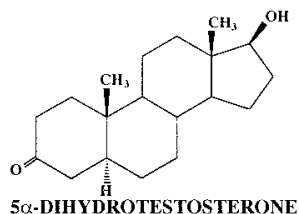

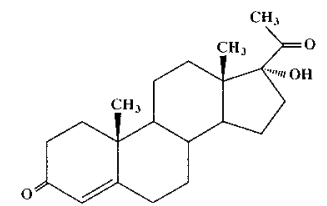

17 $\alpha$-HYDROXPROGESTERONE

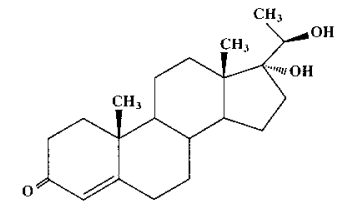

17\%,20ß-DIHYUROXYPROGESTERONE

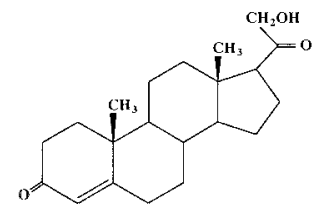

11-DEOXYCORTICOSTERONE

FIGURE 2. Diverse steroids are active in vertebrates. Testosterone, $5 \alpha$-DHT,

$11 \beta$-hydroxytestosterone and 11-ketoT have high affinity for fish AR. However, in fish, the biologically active androgen is 11 -ketoT. In mammals, the biologically active androgens are $5 \alpha$-DHT and testosterone. However, in mammals, $\Delta 5$-androstenediol has both androgenic and estrogenic activity. In fish, $17 \alpha, 20 \beta$-dihydroxyprogesterone, $17 \alpha, 20 \beta, 21$ -

trihydroxyprogesterone, progesterone, 11-deoxycorticosterone (21-hydroxyprogesterone), and $17 \alpha$-hydroxyprogesterone have high affinity for the PR. The biologically active progestin in fish is $17 \alpha, 20 \beta$-dihydroxyprogesterone, which induces the final stages of spermatogenesis in the testis. In birds and mammals, steroids with $17 \alpha$-hydroxy substituents have less than $1 \%$ of the affinity for the progesterone receptor than that of progesterone. In amphibia, birds and mammals, 11-deoxycorticosterone is a mineralocorticoid.

$11 \beta$-HSD changed from regulating the synthesis of the active androgen to regulating cellular glucocorticoid levels, which allows aldosterone to regulate the mineralocorticoid response in the kidney and is permissive for androgen synthesis in the testis.

$17 \alpha, 20 \beta$-Dihydroxyprogesterone (Fig. 2), $17 \alpha$, $20 \beta, 21$-trihydroxyprogesterone, progesterone, $17 \alpha$ hydroxyprogesterone and 11-deoxycorticosterone (21-hydroxyprogesterone) have high affinity for a nuclear receptor in eel (Todo et al. 1999), which has closest sequence similarity to the PR (Fig. 1 and Todo et al. (1999)). However, of these steroids, it is $17 \alpha, 20 \beta$-dihydroxyprogesterone that induces the final stages of spermatogenesis in the testis. In birds and mammals, steroids with $17 \alpha$-hydroxy substituents have less than $1 \%$ of the affinity for the progesterone receptor than that of progesterone (Smith et al. 1974). Thus, like androgens, there is a change in the biologically active progestin during the transition from fish to land animals.

Trout GR-type 1 (Colombe et al. 2000) which is orthologous to the aldosterone receptor does not have high affinity for aldosterone, consistent with evidence that aldosterone is not an active steroid in fish. Trout GR-type 1 binds the potent mammalian glucocorticoids, cortisol and corticosterone, with high affinity. However, trout GR-type 1 also binds 11-deoxycortisol, 21-deoxycortisol, 17-hydroxyprogesterone and $11 \beta$-hydroxyprogesterone with high affinity, indicating that trout GR-type 1 has lower steroid selectivity than mammalian GR-type 1 (Arriza et al. 1987, Rupprecht et al. 1993).

Only limited studies of steroid specificity for trout GR-type 2 have been reported (Ducouret et al. 1995). An important difference between trout and mammalian GRs is that cortisone has about $50 \%$ of cortisol's affinity for trout GR and less than $1 \%$ of 
cortisol's affinity for mammalian GR (Arriza et al. 1987, 1988).

The differences in steroids that activate receptors in fish and land animals have important implications for mammalian physiology. Steroids that are active in fish or were active in ancestral vertebrates may still have activity in mammals, but in a different context. Recognition of androgens and estrogens by an ancestral AR and ER may explain recent findings for crossrecognition of steroids by the mammalian AR and ER. Chang's laboratory found that estradiol regulates androgen-responsive genes by binding to the AR (Yeh et al. 1998), and $\Delta 5$-androstenediol can regulate estrogen-responsive genes by binding to the ER (Miyamato et al. 1998). Thus, a steroid with a saturated A-ring that contains a C-3 alcohol can active the ER. $\Delta 5$-Androstenediol or other $\Delta 5$-steroids may have regulated steroid-responsive transcription early in vertebrate evolution. It will be interesting to determine if $\Delta 5$-androstenediol and other $\Delta 5$-steroids activate the AR, ER, GR or PR in fish.

\section{Environmental implications}

The evidence that fish respond to steroids that are not active in mammals implies that there will be differences between fish and other animals in responses to some xenobiotics, which has important environmental implications. For example, a chemical may bind to more than one hormone receptor and/or enzyme in fish and, thus, have multiple effects on the endocrine system.

Compounds that inhibit steroid-metabolizing enzymes can have different effects on steroidmediated gene expression in fish and mammals. For example, in mammals, carbenoxolone has glucocorticoid and mineralocorticoid activity due to inhibition of 11ß-HSD (Baker \& Fanestil 1991, Monder 1991, Baker 1995, Edwards et al. 1996, Funder 1997). In fish, inhibition of $11 \beta$-HSD by carbenoxolone would lower the concentration of 11-keto T, and carbenoxolone would appear to be an anti-androgen.

The aqueous environment of fish would increase their exposure to xenobiotics, compared with that of land animals. Binding of these chemicals to fish ER, other nuclear receptors and other classes of hormone receptors and enzymes (Baker 1996, 2001) was likely to be important in their evolution. Considering the complexity of the steroid response in animals, including cross-talk in the transcriptional response among steroids and other hormones, one needs to be cautious in extrapolating data from studies on the effects of xenobiotics in mammals to fish and other phylogenetically distant animals.

\section{REFERENCES}

Altshul SF, Madden TL, Schaffer AA, Zhang Z, Miller W \& Lipman DJ 1997 Gapped BLAST and PSI-BLAST: a new generation of database search programs. Nucleic Acids Research 25 2167-2173.

Arriza JL, Weinberger C, Cerelli G, Glaser TM, Handelin BL, Housman DE \& Evans RM 1987 Cloning of human mineralocorticoid receptor complementary DNA: structural and functional kinship with the glucocorticoid receptor. Science 237 268-275.

Arriza JL, Simerly RB, Swanson LW \& Evans RM 1988 The neuronal mineralocorticoid receptor as a mediator of glucocorticoid response. Neuron 1 887-900.

Baker ME 1995 Endocrine activity of plant-derived compounds: an evolutionary perspective. Proceedings of the Society for Experimental Biology and Medicine 208 131-138.

Baker ME 1996 Unusual evolution of $11 \beta$ - and $17 \beta$ hydroxysteroid and retinol dehydrogenases. BioEssays $\mathbf{1 8}$ 63-70.

Baker ME 1997 Steroid receptor phylogeny and vertebrate origins. Molecular and Cellular Endocrinology 135 101-107.

Baker ME 2001 Evolution of $17 \beta$-hydroxysteroid dehydrogenases and their role in androgen, estrogen and retinoid action. Molecular and Cellular Endocrinology 171 211-215

Baker ME \& Fanestil DD 1991 Licorice, computer-based analyses of dehydrogenase sequences and the regulation of steroid and prostaglandin action. Molecular and Cellular Endocrinology 78 C99-C102.

Borg B 1994 Androgens in teleost fishes. Comparative Biochemistry and Physiology 109C 219-245.

Chambon P 1996 A decade of molecular biology of retinoic acid receptors. FASEB Fournal 10 940-954.

Colombe L, Fostier A, Bury N, Pakdel F \& Guiguen Y 2000 A mineralocorticoid-like receptor in the rainbow trout, Oncorhynchus mykiss: cloning and characterization of its steroid binding domain. Steroids 65 319-328.

DeGroot LJ 1995 Endocrinology. Philadelphia: WB Saunders.

Ducouret B, Tujague M, Ashraf J, Mouchel N, Servel N, Valotaire Y \& Thompson EB 1995 Cloning of a teleost fish glucocorticoid receptor shows that it contains a deoxyribonucleic acid-binding domain different from that of mammals. Endocrinology 136 3774-3783.

Edwards CR, Benediktsson R, Lindsay RS \& Seckl JR 199611 Beta-hydroxysteroid dehydrogenases: key enzymes in determining tissue-specific glucocorticoid effects. Steroids $\mathbf{6 1}$ 263-269.

Enmark E \& Gustafsson J-A 1996 Orphan nuclear receptor: the first eight years. Molecular Endocrinology 10 1293-1307.

Escriva H, Safi R, Hanni C, Langlois M-C, Saumitou-Laprade P, Stehelin D, Capron A, Pierce R \& Laudet V 1997 Ligand binding was acquired during evolution of nuclear receptors. PNAS 94 6803-6808.

Escriva H, Delaunay F \& Laudet V 2000 Ligand binding and nuclear receptor evolution. BioEssays 22 717-727.

Evans R 1988 The steroid and thyroid hormone receptor superfamily. Science 240 889-895.

Feng D-F \& Doolittle RF 1990 Progressive alignment and phylogenetic tree construction of protein sequences. Methods in Enzymology 183 375-387.

Fitch WM \& Margoliash E 1967 The construction of phylogenetic trees. Science 214 149-159.

Funder JW 1996 Mineralocorticoid receptors in the central nervous system. Fournal of Steroid Biochemistry and Molecular Biology 64 179-183. 
Funder JW 1997 Glucocorticoid and mineralocorticoid receptors: biology and clinical relevance. Annual Reviews of Medicine 48 231-240.

Giguere V 1999 Orphan nuclear receptors: from gene to function. Endocrine Reviews 20 689-725.

Glass CK 1994 Differential recognition of target genes by nuclear receptor monomers, dimers, and heterodimers. Endocrine Reviews 15 391-407.

Ikeuchi T, Todo T, Kobayashi T \& Nagahama Y 1999 cDNA cloning of a novel androgen receptor subtype. Fournal of Biological Chemistry 274 25205-25209.

Laudet V 1997 Evolution of the nuclear receptor superfamily: early diversification from an ancestral orphan receptor. Fournal of Molecular Endocrinology 19 207-226.

Luo J, Sladek R, Bader JA, Matthyssen A, Rossant J \& Giguere V 1997 Placental abnormalities in mouse embryos lacking the orphan nuclear receptor ERR-beta. Nature $\mathbf{3 8 8}$ 778-782.

Mangelsdorf DJ, Thummel C, Beato M, Herrlich P, Schutz G, Umesono K, Blumberg B, Kastner P, Mark M, Chambon P \& Evans RM 1995 The nuclear receptor superfamily: the second decade. Cell 83 835-839.

Miura T, Yamauchi K, Takahashi H \& Nagahama Y 1991 Hormonal induction of all stages of spermatogenesis in vitro in the male Japanese eel (Anguilla japonica). PNAS $\mathbf{8 8}$ 5774-5778.

Miyamoto H, Yeh S, Lardy H, Messing E \& Chang C 1998 $\Delta 5$-Androstenediol is a natural hormone with androgenic activity in human prostate cancer cells. PNAS 95 11083-11088.

Monder C 1991 Corticosteroids, receptors, and the organspecific functions of $11 \beta$-hydroxysteroid dehydrogenase. FASEB Fournal 5 3047-3054.

Pratt WB \& Toft DO 1997 Steroid receptor interactions with heat shock protein and immunophilin chaperones. Endocrine Reviews 18 306-360.

Ruel JMHM \& De Kloet ER 1985 Two receptor systems for corticosterone in rat brain: microdistribution and differential occupancy. Endocrinology 117 2505-2512.

Rupprecht R, Ruel JMHM, van Steensel B, Spengler D, Soder M, Berning B, Holsboer F \& Damm K 1993 Pharmacological and functional characterization of human mineralocorticoid and glucocorticoid receptor ligands. European Fournal of Pharmacology 247 145-154.

Shu D-G, Luo H-L, Conway Morris S, Zhang X-L, Hu S-X, Chen L, Han J, Zhu M, Li Y \& Chen L-Z 1999 Lower Cambrian vertebrates from south China. Nature 402 42-46.

Smith HE, Smith RG, Toft DO, Neegaard JR, Burrows EP \& O'Malley BW 1974 Binding of steroids to progesterone receptor proteins in chick oviduct and human uterus. Fournal of Biological Chemistry 249 5924-5932.

Takeo J \& Yamashita S 1999 Two distinct isoforms of cDNA encoding rainbow trout androgen receptors. Fournal of Biological Chemistry 274 5674-5680.

Thornton JW \& Kelley DB 1998 Evolution of the androgen receptor: structure-function implications. BioEssays $\mathbf{2 0}$ 860-869.

Todo T, Ikeuchi T, Kobayashi T \& Nagahama Y 1999 Fish androgen receptor: cDNA cloning, steroid activation of transcription in transfected mammalian cells, and tissue mRNA levels. Biochemical and Biophysical Research Communications 254 378-383.

Todo T, Ikeuchi T, Kobayashi T, Kajiura-Kobayashi H, Suzuki K, Yoshikuni M, Yamauchi K \& Nagahama Y 2000 Characterization of a testicular $17 \alpha, 20 \beta$-dihydroxy-4pregnen-3-one (a spermiation-inducing steroid in fish) receptor from a teleost, Japanese eel (Anguilla japonica). FEBS Letters 465 12-17.

Vanacker JM, Bonnelye E, Delmarre C, Cavailles V \& Laudet V 1999a Transcriptional activities of an orphan nuclear receptor ERRa. Molecular Endocrinology 13 764-773.

Vanacker JM, Pettersson K, Gustafsson J-A \& Laudet V 19996 Transcriptional targets shared by estrogen receptor-related receptors (ERRs) and estrogen receptor (ER) $\alpha$ but not by ERß. EMBO Fournal 18 4270-4279.

Xie W, Hong H, Yang NN, Lin RJ, Simon CM, Stallcup MR \& Evans RM 1999 Constitutive activation of transcription and binding of coactivator by estrogen-related receptors 1 and 2. Molecular Endocrinology 13 2151-2162.

Yeh S, Miyamoto H, Shima H \& Chang C 1998 From estrogen to androgen receptor: A new pathway for sex hormones in prostate. PNAS 95 5527-5532.

RECEIVED IN FINAL FORM 11 November 2000 ACCEPTED 22 November 2000 